\title{
Peningkatan Kesantunan Bahasa Anak Usia Dini melalui Media Pembelajaran Interaktif Budaya Jawa
}

\author{
Elina Intan Apriliani ${ }^{1}$, Kartika Yuni Purwanti ${ }^{2}$, Rosalina Wahyu Riani ${ }^{3}$ \\ Pendidikan Guru Pendidikan Anak Usia Dini, Universitas Ngudi Waluyo \\ DOI: $\underline{10.31004 / o b s e s i . v 5 i 1.319}$
}

\begin{abstract}
Abstrak
Penelitian ini bertujuan untuk menghasilkan produk video media pembelajaran interaktif berlatar belakang budaya Jawa yang layak dan efektif dalam meningkatkan kesantunan bahasa peserta didik PAUD Pelangi Nusantara 5, Gedanganak, Kecamatan Ungaran, Semarang. Penelitian ini menggunakan langkah pengembangan (Research \& Development). Design pengembangan ini meliputi 8 langkah yaitu, Analisis, Perancangan Desain, Implementasi, Pengujian, Validasi Ahli, Revisi, Perbaikan Media, dan Produk. Hasil penelitian ini menunjukkan bahwa, video media pembelajaran interaktif yang berlatar belakang budaya Jawa ini telah divalidasi oleh ahli media, ahli materi dengan kategori "baik". Berdasarkan hasil kelayakan media video pada uji coba media video diperoleh hasil dengan presentase 92,5\% dengan kategori baik sedangkan nilai Uji coba kelompok kecil diperoleh hasil, nilai mean sebelum menggunakan media 50,2\% dan nilai sesudah menggunakan media $79,1 \%$, sehingga ada peningkatan $28,9 \%$ berarti ada perbedaan yang signifikan antara sebelum menggunakan media video pembelajaran dan sesudah menggunakan media video pembelajaran. Rata-rata perbedaan (sesudah-sebelum) 28,9\% berarti dapat disimpulkan bahwa media video pembelajaran interaktif bermuatan Budaya Jawa ini dapat digunakan untuk meningkatkan kesantunan bahasa anak usia dini.
\end{abstract}

Kata Kunci: pembelajaran interaktif; budaya jawa, bahasa jawa; kesantunan bahasa; anak usia dini

\begin{abstract}
This study aims to produce a video of interactive learning media that is feasible and effective in increasing the language politeness of students of PAUD Pelangi Nusantara 5, Gedanganak, Ungaran District, Semarang. This research uses development steps (Research \& Development). This development design includes 8 steps namely, Analysis, Design, Implementation, Testing, Expert Validation, Revision, Media Improvement, and Products. The results of this study indicate that, interactive learning media videos are validated by use according to media experts, material experts in the "good" category. Based on the results of the feasibility of video media on video media trials obtained results with a percentage of $92.5 \%$ with a good category while the value of small group trials obtained results, the mean value before using the media $50.2 \%$ and the value after using the media $79.1 \%$, so there is an increase of $28.9 \%$ means there is a significant difference between before using instructional video media and after using instructional video media. The average difference (after-before) $=28.9 \%$ means that it can be concluded that the Javanese culture learning video media can be used to improve the language politeness of early childhood.
\end{abstract}

Keywords: interactive learning; javanese culture; javanese language; politeness of language; early childhood

Copyright (c) 2020 Elina Intan Apriliani, Kartika Yuni Purwanti , Rosalina Wahyu Riani

$\triangle$ Corresponding author :

Email Address : elina.bee06@gmail.com (Kadipiro Margodadi Seyegan Sleman)

Received 11 November 2019, Accepted 30 December 2019, Published 16 May 2020 


\section{PENDAHULUAN}

Fenomena berbahasa pada generasi millennial kian jauh dari sikap kesantunan berbahasa. Bahasa yang santun semakin langka khususnya di lingkungan masyarakat Jawa, sehingga berdampak pada sikap santun masyarakat khususnya sikap santun anak usia dini. Sesuai dengan temuan penelitian dari Subroto (Subroto, Dwirahardjo, \& Setiawan, 2008) bahwa generasi muda Jawa sudah tidak mampu berbahasa Jawa dengan benar dan tepat. Penelitian lain tentang kesantunan bahasa sudah banyak dilakukan, penelitian dari Hestiyana (Hestiyana, 2018) mendeskripsikan bentuk kesantunan tindak direktif pada tuturan anak dan bentuk kesantunan tindak tuturan orang tua. Selanjutnya penelitian dari Hamzah (Hamzah, Hasan, \& Adama, 2011) tentang kesantunan pada penggunaan bahasa yang halus, sopan, lemah lembut serta tidak menyinggung perasaan pendengar, serta menganalisis tentang penggunaan kata dan ujaran santun di kalangan remaja sekolah menengah. Berbeda dengan penelitian Hamzah, penelitian ini lebih menitikberatkan pada kesantuan bahasa pada anak usia dini.

Kesantunan berbahasa juga merupakan indikator pada pendidian karakter. Pendidikan karakter yang sesuai untuk manusia Indonesia adalah sesuai dengan Dasar Negara Pencasila. Hal ini mengharuskan penyelenggara pendidikan menata ulang proses pendidikan karakter agar setiap individu dari masyarakat dan bangsa ini memiliki karakter yang diharapkan Pancasila. Senada dengan Koesoema (Koesoema, 2007) yang mengungkapkan bahwa pendidikan karakter bertujuan untuk menanamkan nilai-nilai kebaikan serta tidak hanya memiliki kepandaian dalam berfikir tetapi juga respek terhadap lingkungan dan melatih potensi diri anak agar dapat berkembang kearah yang positif.

Salah satu pengaruh kemahiran berbahasa anak adalah pola asuh orang tua. Proses pendidikan dan pembentukannya dapat dilakukan pada tiga institusi pendidikan sebagai tripusat pendidikan, yaitu sekolah, masyarakat, dan keluarga. Dalam konteks masyarakat Jawa, keluarga Jawa khususnya, model pendidikan dan pembentukan karakter tercermin dari model pengasuhan dan model pendidikan yang dilakukan oleh orang tua dan pendidik. Berbagai model pengasuhan dan model pendidikan Jawa yang sudah dilakukan diyakini memiliki kontribusi positif bagi pendidikan dan pembentukan karakter. Salah satu pembentukan karakter yaitu pembiasaan kesantunan bahasa. Kesantunan bahasa seseorang itu dapat dilihat dari segi tingkah laku dan penggunaan bahasanya (Wilian, 2006). Setiap bahasa memiliki cara-cara tertentu untuk menunjukkan sikap hubungan antara orang yang berbicara dan lawan bicaranya yang dapat menunjukkan tingkat kesantunan di antara kedua belah pihak.

Bagi orang Jawa, budaya yang dominan adalah budaya Jawa, budaya yang sejak kecil mereka kenal. Dalam lingkungan keluarga Jawa mentradisikan kesantunan berbahasa dapat membentuk generasi bangsa yang berkarakter (Mustika, 2013). Bagi orang Jawa bagaimana mereka mendidik karakter anak tentunya akan disesuaikan dengan budaya yang mereka yakini, yaitu budaya Jawa. Bagi para orang tua Jawa, mereka tidak hanya memberikan konsep kepada anak-anaknya tentang karakter apa dan mana yang dianggap sesuai oleh masyarakatnya, tetapi juga berusaha untuk menjalankannya (Idrus, 2012). Menurut Wadji (Wadji, 2013) Bahasa Jawa dikenal dengan tingkat tutur bahasa "tingkat tutur tinggi" dan ngoko "tingkat tutur rendah". Karena adanya tingkat tutur bahasa dan ngoko, bahasa jawa diidentifikasi dan diklasifikasikan sebagai bahasa yang hidup dalam situasi diglosia dan memungkinkan para penuturnya memperlihatkan keakraban, penghormatan dan jenjang hierarki dengan sesama anggota masyarakat.

Pola asuh yang benar akan memberikan perkembangan yang baik bagi anak, khususnya perkembangan bahasa. Pola asuh yang salah akan memberikan efek yang negatif pada anak. Robbiyah, Ekasari, \& Witarsa (2018) dalam penelitiannya mendapatkan bahwa dalam mendisiplinkan anak dengan cara yang berbeda- beda setiap harinya, dengan cara ini mereka bisa mendisiplinkan dengan pola asuh yang tidak berlebihan karena anak disini tidak terlalu dipaksa untuk mematuhi peraturan ini, hanya anak diajarkan setiap hari untuk belajar bangun pagi dan makan ketika mau berangkat sekolah dengan perasaan yang gembira. 
Dalam penelitian ini pola asuh dan pembiasaan bahasa jawa yang digunakan di dalam keluarga jawa saat ini lebih banyak menggunakan bahasa Indonesia, sehingga anak mengalami kesulitan untuk belajar kesantunan bahasa dalam budaya Jawa. Penelitian Cahyadi (Cahyadi, 2018) mengungkapkan tingkat tutur bahasa Jawa siswa mengalami kesulitan dalam bahasa Jawa dengan baik dikarenakan penerapan unggah-ungguh sangat sulit dan kaku kemudian banyak guru yang kurang memahami dan menguasai materi karena tidak didukung oleh latar belakang pendidikan bahasa Jawa. Nilai kesopanan salah satunya dapat dipelajari dari mata pelajaran Bahasa Jawa dalam materi unggah-ungguh Bahasa Jawa. Unggah-ungguh Bahasa Jawa tidak hanya mengajarkan kesantunan bertutur namun juga mengajarkan kesopanan bertingkah laku (Didaktika, 2006). Dalam penelitian ini, penelitian ini untuk meningkatkan kesantunan bahasa anak dalam bahasa jawa halus untuk anak usia dini.

Jumanto (Jumanto, 2014) berpendapat tentang probabilitas dalam penggunaan bahasa tentang bagaimana seorang pembicara yang kompeten harus menyadari untuk kesopanan atau untuk persahabatan dan mampu menghindari ketidaksopanan sedangkan dalam penelitian ini mengarah kepada cara meningkatkan kesopanan bahasa anak usia dini. Strategi yang digunakan dalam penelitian ini mengacu pada pendapat Penelope (Brown, Levinson, \& Gumperz, 1987) yang menyatakan "Politeness Strategies are used to formulate messages in order to save the hearer's face when face treathening acts are inevitable or desired." Selain itu mengacu pada pendapat Suryabrata (Suryabrata, 2006) menyatakan bahwa psikologi dimasukkan untuk memahami sesama manusia, dalam hal ini psikologi kepribadian menempati posisi sentral agar memberi bekal dalam kegiatan sehari-hari.

Dalam lingkungan sekolah PAUD, mayoritas pendidik PAUD mengajarkan pembelajaran bahasa Jawa masih dalam tahap dasar, seperti pengenalan angka dan kalimat sederhana dalam bahasa Jawa tanpa menggunakan media pembelajaran. Bahkan PAUD Pelangi Nusantara 5 Kecamatan Ungaran Kabupaten Semarang merupakan salah satu sekolah yang belum menggunakan media yang inovatif dan masih mengajarkan pembelajaran bahasa Jawa pada tahap dasar. Sedangkan pendidikan saat ini sudah mulai berkembang, sehingga kualitas pendidikan memerlukan terobosan baru, salah satunya adalah inovasi pembelajaran. Solusi yang peneliti tawarkan pada penelitian ini yaitu meningkatkan kesantunan bahasa anak melalui video pembelajaran interaktif bermuatan budaya Jawa.

Berdasarkan latar belakang masalah diatas, peneliti dapat mengidentifikasi beberapa masalah yaitu pembiasaan bahasa yang digunakan keluarga menggunakan bahasa Indonesia sehingga anak merasa kesulitan untuk belajar kesantunan bahasa dalam budaya Jawa dan pendidik PAUD masih mengajarkan pembelajaran bahasa Jawa pada tahap dasar serta tanpa menggunakan media pembelajaran. Peneliti mengembangkan video pembelajaran ini bertujuan untuk mengembangkan media pembelajaran video interaktif budaya Jawa, mengetahui kelayakan media pembelajaran video dan meningkatkan kesantunan bahasa anak dalam budaya Jawa.

\section{METODOLOGI}

Pendekatan yang digunakan dalam penelitian ini adalah metode penelitian pengembangan (Research \& Development) (Arikunto, 2009). Sampel penelitian adalah Anak Usia Dini PAUD Pelangi Nusantara 5 Ungaran. Design pengembangan ini meliputi 8 langkah yaitu, Analisis, Perancangan Desain, Implementasi, Pengujian, Validasi Ahli, Revisi, Perbaikan Media, dan Produk. Uji coba kelompok kecil melibatkan 15 anak di PAUD Nusantara 5 Ungaran. Analisis data berdasarkan uji coba kelompok kecil dengan 15 responden. Uji coba kelompok besar melibatkan 20 anak di PAUD Pelangi Nusantara 5 Ungaran.

Gambaran tahapan Pengembangan Metode Penelitian ini adalah sebagai berikut : 


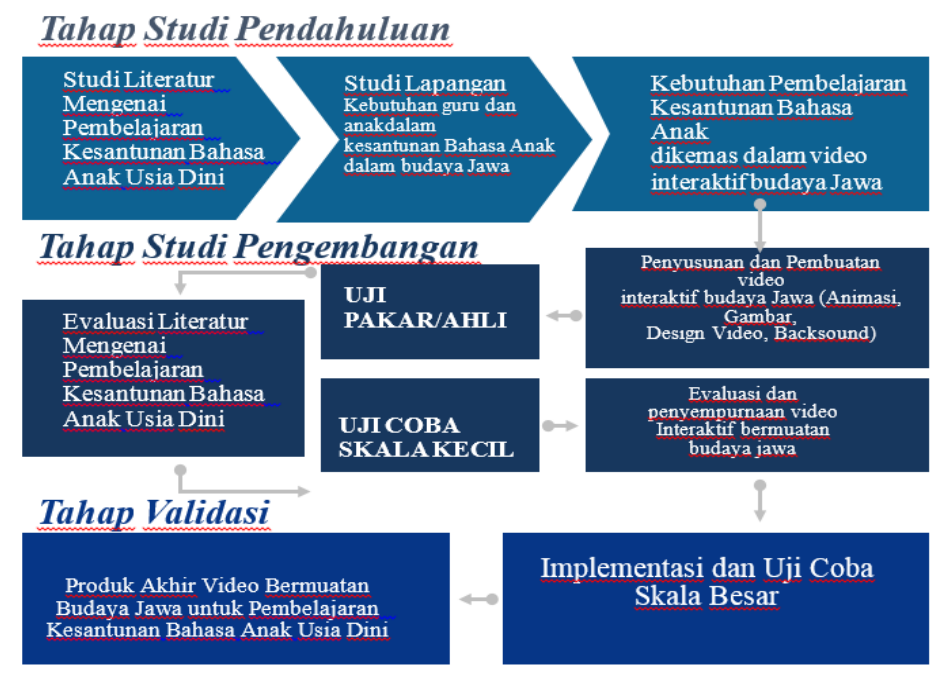

\section{Gambar 1. Tahapan Metode Penelitian}

Teknik pengumpulan data dengan cara angket, observasi dan dokumentasi. Analisis data validasi ahli diperoleh dari penilaian ahli materi, media dan desain pembelajaran berdasarkan angket yang diberikan. Data tersebut kemudian dianalisis dengan rumus:

$$
\text { Hasil }=\frac{\text { skor yang diperoleh }}{\text { skor maksimal }} \times 100 \%
$$

Tabel 1. Kategori Kelayakan Produk Media Video

\begin{tabular}{lll}
\hline Tingkat Pencapaian & Kualifikasi & Keterangan \\
\hline $85 \%-100 \%$ & Sangat baik & Tidak perlu direvisi \\
$75 \%-84 \%$ & Baik & Tidak perlu direvisi \\
$65 \%-74 \%$ & Cukup & Direvisi \\
$55 \%-64 \%$ & Kurang & Direvisi \\
$0-54 \%$ & Kurang sekali & Direvisi \\
\hline
\end{tabular}

\section{HASIL DAN PEMBAHASAN}

Hasil dari penelitian pengembangan ini adalah produk media video pembelajaran interaktif bermuatan budaya Jawa. Tahapan penelitian dilakukan meliputi Tahap Studi Pendahuluan, Tahap Studi Pengembangan dan Tahap Validasi.

\section{Tahap Studi Pendahuluan}

Dalam studi pendahuluan peneliti melakukan studi pustaka berupa literatur dan buku media pembelajaran untuk menentukan media yang sesuai dengan kebutuhan penelitian. Karakteristik anak usia dini membutuhkan media pembelajaran yang dapat mengkonkretkan konsep-konsep abstrak seperti kesantunan bahasa.

\section{Tahap Studi Pengembangan}

Tahap studi pengembangan dilakukan dengan membuat media video pembelajaran. Dalam pembuatan video ini tim peneliti menentukan tema pembelajaran yang dibutuhkan dan disesuaikan kebutuhan di lapangan agar mudah diterima oleh anak usia dini. Berikut tahap pembuatan video Pembelajaran Interaktif Budaya Jawa: 


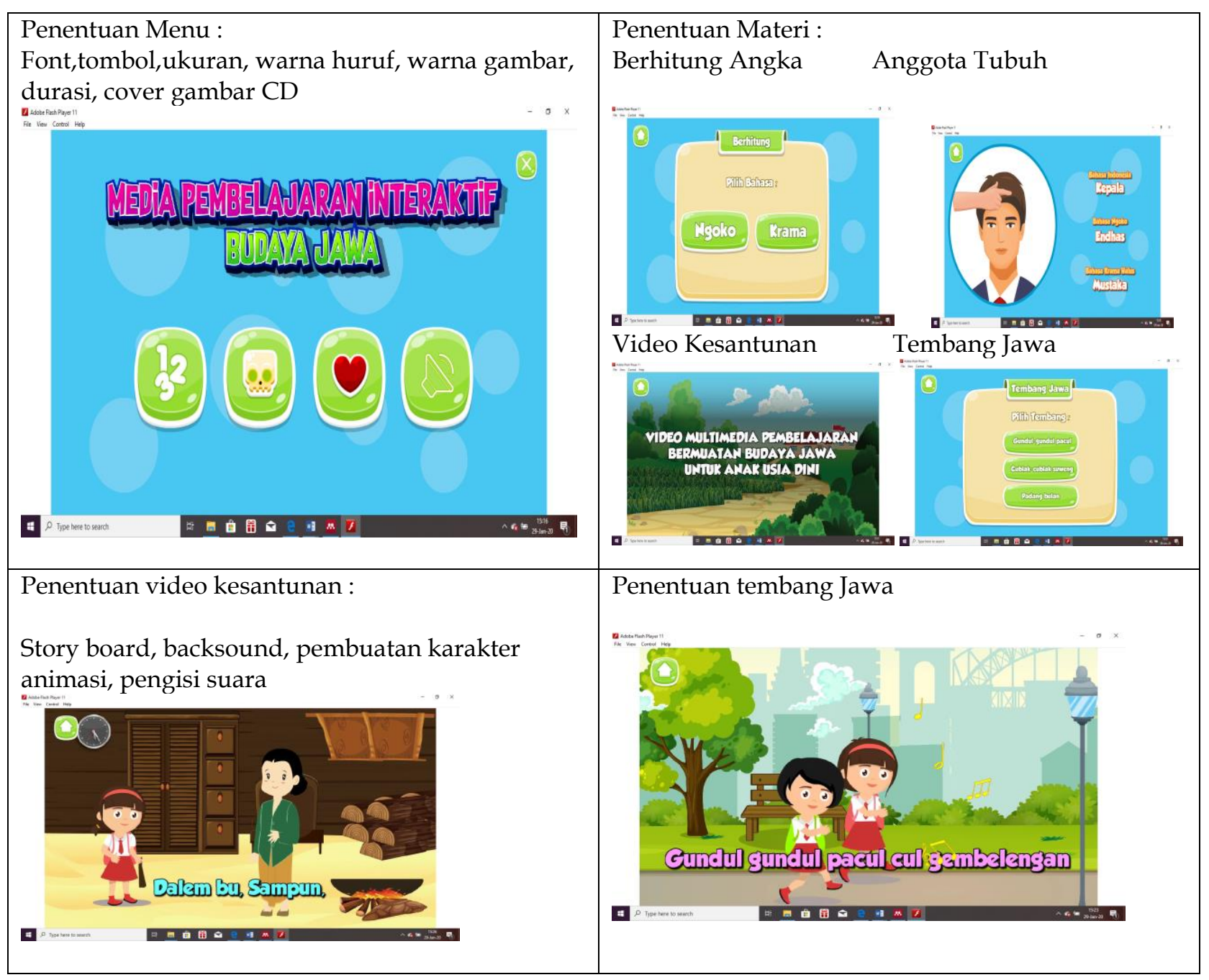

\section{Tahap Validasi}

\section{Gambar 2. Tahap Pengembangan Media Pembelajaran}

Tahap validasi dilakukan setelah video Pembelajaran Interaktif Budaya Jawa selesai dibuat. Berikut ini dipaparkan tentang sajian dan analisis data hasil tanggapan atau penilaian ahli media, ahli materi, uji coba kelompok kecil dan uji coba kelompok besar.

a. Validasi Ahli Media: Validasi ahli media adalah Bapak Yohannes Romando Sipayung, S.Kom.,M.Kom. Hasil analisis data validasi ahli media diperoleh presentase $80 \%$. Jika disesuaikan dengan tabel kelayakan, maka produk yang dikembangkan masuk dalam kualifikasi "Baik".

b. Validasi Ahli Materi: Validasi ahli materi dilakukan oleh Ibu Anni Malihatulhawa, M.Pd. Hasil analisis data validasi ahli materi diperoleh nilai presentase 92,5\%. Jika disesuaikan dengan tabel kelayakan, maka produk yang dikembangkan masuk kedalam kualifikasi "sangat baik".

Tabel 2. Revisi Ahli Media

\begin{tabular}{llll}
\hline No & Uji Coba & Bagian yang perlu direvisi & Bagian yang telah direvisi \\
\hline 1. & Ahli Media &
\end{tabular}


c. Uji coba Produk

Uji coba kelompok kecil melibatkan 15 anak di PAUD Nusantara 5 Ungaran. Analisis data berdasarkan uji coba kelompok kecil dengan 15 responden diperoleh rata-ratanya yaitu: $85 \%$. Yang berarti media video ini dinyatakan valid sebagai media pembelajaran. Sedangkan nilai rata-rata pre test pada uji coba kelompok kecil sebelum menggunakan media video sebesar $50,5 \%$.

Uji coba kelompok besar melibatkan 20 anak di PAUD Pelangi Nusantara 5 Ungaran. Analisis data berdasarkan uji coba kelompok besar dengan 20 responden diperoleh rataratanya yaitu $92,5 \%$. Sedangkan nilai rata-rata post test pada uji coba kelompok besar sesudah menggunakan media video sebesar $76,5 \%$.

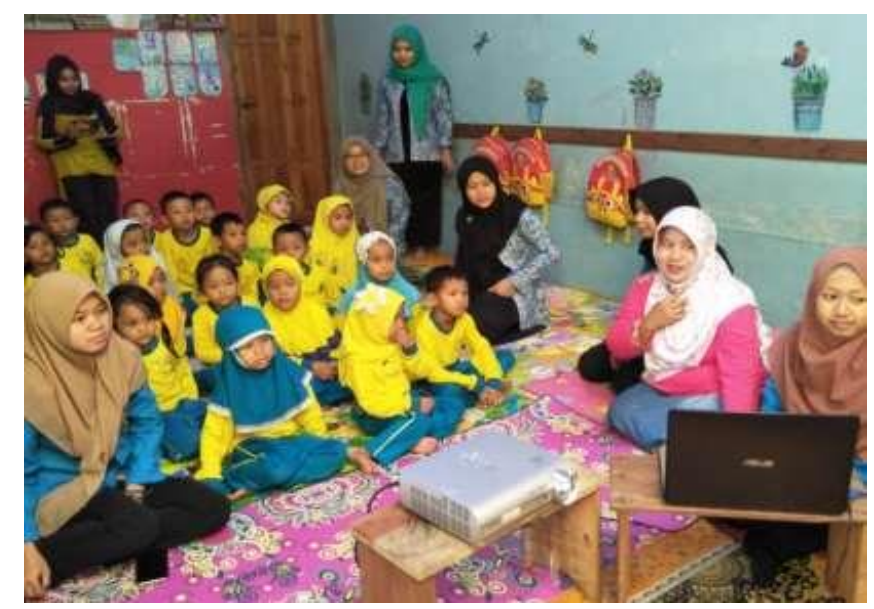

Gambar 3. Uji Kelompok Besar

Berdasarkan hasil kelayakan media video Pembelajaran Interaktif Budaya Jawa pada hasil validasi ahli diperoleh hasil 92,5\% dengan kategori "sangat baik" sehingga dapat disimpulkan bahwa media video ini layak digunakan untuk media pembelajaran. Sedangkan nilai uji coba kelompok kecil (sebelum menggunakan media) dan kelompok besar (sesudah menggunakan media) terdapat peningkatan $26 \%$ yang berarti ada perbedaan yang signifikan antara sebelum dan sesudah menggunakan media video pembelajaran. Dapat ditarik kesimpulan bahwa penggunaan media video pembelajaran interaktif ini dapat meningkatkan kesantunan bahasa anak usia dini dalam budaya Jawa.

\section{Pembahasan}

Penggunaan media dalam pembelajaran memang sesuai dengan karakteristik anak usia dini. Anak usia dini belum bisa memahami konsep-konsep abstrak. Oleh karena itu, pendidik PAUD harus banyak menggunakan media pada saat memberikan konsep-konsep abstrak seperti kesantunan berbahasa. Hal ini sesuai dengan penelitian yang dilakukan oleh Fauziddin (Fauziddin, 2015) tentang penggunaan media benda konkret dalam pembelajaran klasifisikasi benda pada anak usia dini. Walaupun penelitian Fauziddin dan penelitian ini berbeda media, namun ketercapaian konsep-konsep yang diberikan oleh guru ternyata dapat lebih dicapai dengan menggunakan bantuan media. Selain itu penelitian yang dilakukan oleh Putra (Putra \& Ishartiwi, 2015) tentang pengembangan multimedia pembelajaran interaktif mengenal angka dan huruf untuk anak usia dini juga memperkuat penelitian yang dilakukan oleh penulis bahwa pembelajaran akan lebih efektif dilakukan apabila menggunakan media pembelajaran yang menarik dan konkrit bagi anak usia dini.

Media pembelajaran yang dibuat oleh penulis yaitu untuk mengenalkan budaya Jawa kepada anak usia dini, dengan tujuan supaya anak usia dini mengenal budaya daerahnya dalam hal ini budaya Jawa sejak dini. Selain dari aspek bahasa yang dikembangkan, pendidikan karakternya pun dalam hal ini ikut berperan. Peran pendidikan karakter didalam media video Pembelajaran Interaktif Budaya Jawa yaitu mengajarkan sopan dan santun terhadap orang tua/orang yang lebih tua serta teman sebayanya, saling menghormati. 
Media video Pembelajaran Interaktif Budaya Jawa ini berhasil meningkatkan kesantunan berbahasa pada peserta didik PAUD Pelangi Nusantara 5 Ungaran. Keberhasilan ini selain didapatkan dari hasil analisis statistik, juga terlihat secara pengamatan. Pada saat pemberian perlakuan, anak-anak nampak bersemangat dan termotivasi dalam belajar. Anak-anak antusias melihat dan mengamati video Pembelajaran Interaktif Budaya Jawa. Hal ini dapat disebabkan karena karakter animasi yang ada dalam media video berhasil menarik perhatian anak. Rasa senang dan nyaman dapat meningkatkan kemampuan otak untuk menerima informasi yang disampaikan, sehingga pesan edukasi yang ada pada media pembelajaran dapat lebih dicerna oleh anak. Contoh-contoh kesantunan yang dikemas dalam media pembelajaran ini juga memudahkan anak untuk memahami konsep abstrak kesantunan.

Selain itu, media video Pembelajaran Interaktif Budaya Jawa yang juga menampilkan lagu-lagu Jawa, ternyata juga menambah rasa senang pada anak. Stimulus menggunakan lagulagu memang sesuai dengan karakteristik anak usia dini. Anak-anak lebih senang bila semua panca indranya mendapatkan stimulus dan dikemas dengan nada-nada yang menarik. Lagu Gundul-gundul Pacul yang diperdengarkan dalam media pembelajaran ini menambah nilai plus, karena membawa anak-anak untuk lebih mencintai budaya sendiri dari pada budaya luar yang sekarang ini membanjiri lingkungan sekitar anak, terutama di rumah.

Keberlanjutan dampak peningkatan kesantunan berbahasa juga terbawa sampai di rumah. Hal tersebut diketahui setelah dilakukan wawancara dengan orang tua. Anak-anak menjadi terbiasa berbahasa santun baik kepada guru, orangtua, orang dewasa di sekitar anak, bahkan kepada teman-teman di lingkungan sekolah dan rumah. Orang tua juga memberikan respons yang sangat baik setelah mengetahui bahwa sekolah menggunakan media pembelajaran yang menarik seperti media video Pembelajaran Interaktif Budaya Jawa. Saran dan masukan dari orang tua tentang penggunaan media pembelajaran ini adalah, agar dapat dikembangkan lagi untuk mengembangkan aspek-aspek yang lain pada peserta didik.

Tema budaya Jawa yang diangkat dalam media pembelajaran ini dianggap sesuai dengan kebutuhan saat ini, dimana kehidupan masyarakat lebih banyak disuguhi oleh budaya-budaya luar yang belum tentu sesuai dengan adat dan budaya bangsa Indonesia. Antusias orang tua terhadap perubahan perilaku anak ini semakin menguatkan dan memberikan semangat pada para pendidik di PAUD Pelangi Nusantara 5 Ungaran untuk lebih banyak mengembangkan media-media pembelajaran bagi peserta didiknya. Secara umum hasil penelitian ini menunjukkan bahwa penggunaan media video Pembelajaran Interaktif Budaya Jawa ini layak digunakan untuk meningkatkan kesantunan bahasa anak usia dini.

\section{SIMPULAN}

Berdasarkan hasil analisis data, pembahasan dan hasil pengembangan media pembelajaran media video di PAUD Pelangi Nusantara 5 dapat diambil kesimpulan bahwa media pembelajaran video interaktif budaya Jawa telah tervalidasi ahli, validasi ahli media mendapatkan presentase sebesar $80 \%$ dan termasuk dalam kategori "baik", sedangkan validasi ahli materi mendapatkan nilai presentase sebesar 92,5\% dan termasuk dalam kategori "sangat baik". Media pembelajaran video interaktif budaya Jawa juga telah melalui tahap uji coba produk melalui uji coba kelompok kecil dan uji coba kelompok besar terdapat peningkatan $28,9 \%$ yang berarti ada perbedaan yang signifikan antara sebelum dan sesudah menggunakan media video pembelajaran. Dapat ditarik kesimpulan penggunaan media video pembelajaran interaktif ini dapat meningkatkan kesantunan Bahasa anak usia dini dalam budaya Jawa.

\section{UCAPAN TERIMA KASIH}

Penelitian ini mendapatkan hibah Dikti dengan skim Penelitian Dosen Pemula. Penulis mengucapkan terima kasih atas diperolehnya hibah dikti ini untuk memperlancar proses penelitian dengan judul "Peningkatan Kesantunan Bahasa Anak Usia Dini melalui media Pembelajaran Interaktif Budaya Jawa". Penulis mengucapkan terima kasih kepada pengelola Jurnal Obsesi yang telah memberikan kesempatan penulis menerbitkan artikel hasil penelitian yang didanai oleh Dikti. 


\section{DAFTAR PUSTAKA}

Arikunto, S. (2009). Manajemen Penelitian. Jakarta: Jakarta: Rineka Cipta.

Brown, P., Levinson, S. C., \& Gumperz, J. J. (1987). Politeness. https://doi.org/10.1017/CBO9780511813085

Cahyadi, R. (2018). Pembelajaran Bahasa Jawa dalam Membentuk Kesantunan Berbahasa di MI Muhammadiyah Arenan Kecamatan Kaligondang Kabupaten Purbalingga. Thesis.

Didaktika. (2006). Peran Pembelajaran Unggah-Ungguh Bahasa Jawa dalam Penanaman Nilai Sopan Santun di Sekolah Dasar. DIDAKTIKA.

Fauziddin, M. (2015). Peningkatan Kemampuan Klasifikasi Melalui Media Benda Konkret pada Anak Kelompok A1 di TK Cahaya Kembar Bangkinang Kampar. Jurnal Obsesi: Jurnal Pendidikan Anak Usia Dini, 2(1). https:/ / doi.org/10.31004/obsesi.v1i2.65

Hamzah, zaitul azma zainon, Hasan, ahmad fuad mat, \& Adama, M. N. H. M. (2011). Kesantunan bahasa dalam kalangan remaja sekolah menengah. Jurnal Bahasa, 11(2), 321338.

Hestiyana, H. (2018). Kesantunan Tindak Direktif pada Tuturan Anak dan Orang Tua di Desa Ngumbul Kabupaten Pacitan. Madah: Jurnal Bahasa Dan Sastra. https://doi.org/10.26499/madah.v9i1.713

Idrus, M. (2012). Pendidikan Karakter pada Keluarga Jawa. Jurnal Pendidikan Karakter. https:// doi.org/10.21831/jpk.v0i2.1297

Jumanto. (2014). Towards a Character Language: A Probability in Language Use. Open Journal of Modern Linguistics, 04(02), 333-349. https:/ / doi.org/10.4236/ojml.2014.42027

Koesoema, D. (2007). Pendidikan Karakter: Strategi Mendidik Anak di Zaman Global. In Jakarta: Grasindo.

Mustika, I. (2013). Mentradisikan Kesantunan Berbahasa: Upaya Membentuk Generasi Bangsa yang Berkarakter Ika. Semantik.

Putra, L. D., \& Ishartiwi, I. (2015). Pengembangan Multimedia Pembelajaran Interaktif Mengenal Angka dan Huruf untuk Anak Usia Dini. Jurnal Inovasi Teknologi Pendidikan, 2(2), 169-178. https://doi.org/10.21831/tp.v2i2.7607

Robbiyah, R., Ekasari, D., \& Witarsa, R. (2018). Pengaruh Pola Asuh Ibu terhadap Kecerdasan Sosial Anak Usia Dini di TK Kenanga Kabupaten Bandung Barat. Jurnal Obsesi: Jurnal Pendidikan Anak Usia Dini, 2(1), 74. https:// doi.org/10.31004/ obsesi.v2i1.10

Subroto, D. E., Dwirahardjo, M., \& Setiawan, B. (2008). Endangered Krama and Krama Inggil Varieties of the Javanese Language. Linguistik Indonesia.

Suryabrata, S. (2006). Psikologi Kepribadian.

Wadji, M. (2013). Sistem Kesantunan Masyarakat Jawa. LINGUISTIKA.

Wilian, S. (2006). Tingkat Tutur dalam Bahasa Sasak dan Bahasa Jawa. Wacana, Journal of the Humanities of Indonesia, 8(1), 32. https:// doi.org/10.17510/wjhi.v8i1.245 